$$
\begin{gathered}
\text { 급성음낭증 환아에서 최초 증상발현 후 내원시간에 미치는 인자 } \\
\text { 부산대학교 의과대학 비뇨기과학교실 } \\
\text { 박현준 }{ }^{*} \text { 박남철·이상돈 }
\end{gathered}
$$

\title{
Analysis of Facotrs Associated with the Time to Visit Hospital after Onset of Symptom in Patients with Acute Scrotum
}

\author{
Hyun Jun Park*, Nam Cheol Park and Sang Don Lee \\ Department of Urology, Pusan National University School of Medicine, Busan, Korea
}

\begin{abstract}
The purpose of this study was to evaluate the factors affecting the time elapsed before hospital visit after onset of acute scrotum, to contribute to early recognition of the disease and to improve the testis salvage rate. We evaluated 90 cases of patients under 18 year or age with acute scrotum, who visited the Pusan National University Hospital between March 1997 and March 2006. Clinical data were collected through telephone interviews and surveys of medical records. The time elapsed before hospital visit after onset of symptom were reviewed with regard to the age of their parents, school career and income level of parents, Nunmber of sieblings, both parents' working, age of patients, and the knowledge of their parents about acute scrotum. The mean time passed before hospital visit was $48 \mathrm{hrs}(1 \sim 300 \mathrm{hrs})$. The causative diseases were testicular torsion, acute epididymitis, torsion of appendix testis, acute orchitis. School career of mother, income level, both parents' working and knowledge of their parents about acute scrotum had significant influence on the time passed before hospital visit after onset of symptom. Our results suggest that improvement of the testis salvage rate requires that children, their families and teachers should be aware of this disease and its sequelae through public education projects.
\end{abstract}

Keywords: Scrotum, Testicular torsion, Prognosis

\section{서 론}

급성음낭증이란 내과적 혹은 외과적 응급치료를 요하는 음낭의 모든 병적 상태를 말하며 음낭의 부종과 통증을 주 증상으로 한다. ${ }^{1}$ 급성음낭증의 원인 질환에 대한 감별은 신 체검사와 검사실 검사만으로는 부정확하므로 여러 가지 진

게재결정: 2008년 3월 10일

*교신저자: 박현준, 602-739, 부산대학교 의과대학 비뇨기과학교실, Phone: 051-240-7351, FAX: 051-247-5443, E-mail: joon501@naver.com
단방법들이 이용되고 있으며, 초음파를 이용한 색도플러 초 음파와 고환주사가 진단에 이용됨으로써 과거에 비해 진단 의 정확도가 많이 향상되었다. 원인으로는 고환염전, 부고환 염, 고환염, 탈장 및 음낭외상 등이 있는데 조기에 적절한 치료가 이루어지지 않으면 고환괴사, 고환위축, 고환농양 및 불임 등의 후유증이 발생할 수 있으므로 신속하면서도 정확 한 감별진단과 치료가 필요하다. ${ }^{2}$ 특히 고환염전의 경우 증 상발현 후 수술까지의 시간이 고환의 보존에 절대적 영향을 미치지만 여러 가지 이유에 의해 증상의 발현 후 병원 방문 
까지의 시간이 늦어지는 경우가 많다. 이에 저자들은 증상발 현 후 내원까지의 시간을 여러 인자들에 따라 비교분석하여 급성음낭증 환아의 조기진단 및 치료에 도움이 되고자 한다.

\section{대상 및 방법}

\section{1. 대상 환자}

1997년부터 2006년까지 급성음낭증을 주소로 본원 비뇨 기과를 방문한 18 세 이하의 환아 122 예 중 병력지 검토가 가능한 총 90 예를 대상으로 후향적 연구로 시행하였다. 단, 외상의 병력 및 증거가 확실하였던 경우는 제외하였다.

\section{2. 방법}

최초 증상발현 후 내원까지의 평균시간을 부모의 연령 및 학력수준, 소득수준, 맞벌이 여부, 환아의 나이 및 부모의 급성음낭증에 대한 사전인지여부 등에 따라 비교분석하였으 며 내원시간에 따른 고환보존율을 조사하였다. 내원 당시 진 단은 급성고환통의 발생양상, 복부증상, 배뇨증상, 오심, 구 토, 증상발현시간 및 과거력 등의 병력청취와 프렌징후 (prehn's sign), 거고근반사, 고환의 횡위 등의 신체검사 및 백혈구 증다증 및 소변검사 등의 검사실검사를 시행하였으 며 추가검사로는 색도플러음낭초음파검사 및 고환동위원소 촬영를 시행하였다. 단, 고환동위원소촬영은 검사 준비의 시 간적 제약에 따라 예약 촬영이 가능하였던 환아에서 시행하 였다. 최종 진단은 병력 및 신체검사, 검사실 검사, 색도플 러음낭초음파 검사 및 고환동위원초촬영 등을 시행한 결과 를 종합하여 판단하였으며 급성음낭증의 원인이 고환염전으 로 의심되는 경우는 응급으로 음낭탐색술을 시행하였다.

\section{3. 통계처리}

Kruskall-Wallis test 와 Mann-Whitney test를 이용하여 통계적으로 분석하였고, $\mathrm{p}$ 값이 0.05 미만일 때 통계학적 유 의성이 있는 것으로 판정하였다.

\section{결 과}

총 90예의 급성음낭증 환아에서 증상발현 후 병원도착까 지의 시간은 1 시간부터 300 시간(평균 48 시간)이었다.
Table 1. Characteristics of patients

\begin{tabular}{ll}
\hline \multicolumn{1}{c}{ Parameters } \\
\hline No. of patients & 90 \\
Mean ages (years) & 11.6 \\
Mean arrival time (hours) & 48 \\
No. patients according to cause of acute scrotum \\
Testicular torsion & $34(37.7 \%)$ \\
Acute epididymitis & $32(35.6 \%)$ \\
Torsion of appendix testis & $13(14.4 \%)$ \\
Acute orchitis & $11(12.2 \%)$ \\
\hline
\end{tabular}

\section{1. 급성음낭증의 원인별 분포}

급성음낭증으로 내원한 총 90 례의 원인별 분포를 보면 고 환염전이 34 예(37.7\%)로 가장 많았고, 급성부고환염, 고환 수염전 및 급성고환염이 각각 32 (35.6\%), 13 (14.4\%) 및 11예(12.2\%)였다(Table 1).

\section{2. 증상발현 후 최초 방문한 의료기관}

비뇨기과의원이 42예(47\%)로 가장 많았고 본원 응급실, 본원 비뇨기과 외래, 소아과의원 및 일반의원이 각각 23 예 (26\%), 10예(11\%), 10예(10\%) 및 6예(6\%)였다.

\section{3. 고환염전시 수술시기에 따른 고환 보존율}

시험적 음낭절개술을 시행한 45 예 중 34 예 $(75.5 \%)$ 에서 고환염전으로 진단되었으며 이중 27 예(60\%)에서 고환보존 이 가능하였다. 고환염전 환자의 경우 급성음낭증의 원인이 고환염전이 아닌 다른 질환으로 생각되어져 수술이 늦어진 례는 없었다. 병원도착 후 수술까지 걸린 시간은 평균 4.4시 간이었으며 증상발현 후 수술까지의 시간에 따라 비교 시 6 시간 이내인 23예에서는 모든 예에서 고환보존이 가능하였 으나 6 12시간인 경우는 9예 중 3예(33\%), 그리고 2 24 시간인 경우는 4예 중 1 예(25\%)만이 고환보존이 가능하였 으며 24시간 이상인 5 예에서는 고환의 괴사가 모든 례에서 진행되어 고환절제술을 시행하였다.

\section{4. 부모의 연령에 따른 비교}

아버지의 나이가 30 대 및 40 대에서 각각 57.2시간 및 49.2시간으로 30 대인 경우 내원시간이 늦었으나 통계학적 유의성은 없었으며, 어머니의 나이가 20대인 경우에는 67.5 시간으로 30 대인 경우의 41.2시간이 비해 내원이 늦어졌으 나 통계학적 유의성은 없었다(Table 2). 
Table 2. Mean time to visit hospital after onset of symptom

\begin{tabular}{|c|c|c|}
\hline & $\begin{array}{l}\text { Mean arrival } \\
\text { time (hours) }\end{array}$ & $\mathrm{p}$ value \\
\hline \multicolumn{3}{|l|}{ Age of parents } \\
\hline Father & & $p=0.154$ \\
\hline Thirties & 57.2 & \\
\hline Fourties & 49.2 & \\
\hline Mother & & $p=0.542$ \\
\hline Twenties & 67.5 & \\
\hline Thirties & 41.2 & \\
\hline \multicolumn{3}{|l|}{ School career of parents } \\
\hline Father & & $p=0.324$ \\
\hline University graduate & 48.7 & \\
\hline High school graduate & 45.8 & \\
\hline Middle school graduate & 49.7 & \\
\hline Mother & & $p<0.05$ \\
\hline University graduate & 58.1 & \\
\hline High school graduate & 43.3 & \\
\hline Middle school graduate & 44.2 & \\
\hline Income level (monthly) & & $p<0.05$ \\
\hline$\geq 3,000,000$ won & 65.8 & \\
\hline$\geq 2,000,000$ won, $<3,000,000$ won & n 39.4 & \\
\hline$\geq 1,000,000$ won, $<2,000,000$ won & n 37.2 & \\
\hline$<1,000,000$ won & 97.3 & \\
\hline No. of children & & $p=0.131$ \\
\hline One & 81.8 & \\
\hline Two or more & 30.7 & \\
\hline Working together of parents & & $p<0.05$ \\
\hline Yes & 64.4 & \\
\hline No & 26.3 & \\
\hline Age of patients (years) & & $p=0.247$ \\
\hline Infant $(<1)$ & 18.8 & \\
\hline Preschool child $(\geq 1,<6)$ & 26 & \\
\hline Schoolchild $(\geq 6,<11)$ & 54.6 & \\
\hline Adolescence $(\geq 11)$ & 50.6 & \\
\hline \multicolumn{2}{|c|}{ Knowledge about acute scrotum of parents } & $p<0.05$ \\
\hline Yes & 28.7 & \\
\hline No & 52.9 & \\
\hline
\end{tabular}

\section{5. 부모의 학력에 따른 비교}

부모의 학력에 따라 비교 시 아버지의 학력이 대졸 이상, 고졸 및 중졸 이하인 경우 각각 48.7, 45.8 및 49.7시간이었 고, 어머니의 경우는 각각 58.1, 43.3 및 44.2시간으로 어머 니의 학력이 대졸이상인 경우 내원이 늦어졌다 $(\mathrm{p}<0.05$, Table 2).

\section{6. 소득수준에 따른 비교}

부모의 소득수준에 따라 비교 시 월 100만원 미만, 100 200만원, 200 300만원 및 300만 원대 이상에서 각각 97.3, 37.2, 39.4 및 65.8시간으로 월 소득이 100 만원 미만 인 가정과 300 만 원대 이상인 가정의 환아에서 내원이 늦어
졌다 $(\mathrm{p}<0.05$, Table 2).

\section{7. 자녀의 수에 따른 비교}

자녀가 한명인 경우는 81.8 시간으로 2 명 이상에서의 30.7 시간에 비해 내원까지의 시간이 길어지는 것으로 나타났으 나 통계적 유의성은 없었다(Table 2).

\section{8. 부모의 맞벌이 여부에 따른 비교}

맞벌이 부부인 경우는 64.4시간, 그렇지 않은 경우는 26.3 시간으로 맞벌이 부부인 경우가 내원이 늦어졌다 $(\mathrm{p}$ $<0.05$, Table 2).

\section{9. 환아의 나이에 따른 비교}

생후 1 세 미만의 영아인 경우, 1 세 이상 6 세 미만의 유아 인 경우, 6 세 이상 11 세미만의 학령기인 경우 및 11 세 이상 의 사춘기인 경우 각각 18.8 시간, 26시간, 54.6시간 및 50.6 시간으로 6세 이상에서 내원이 늦었으나 통계적 유의성은 없었다(Table 2).

\section{0. 부모의 급성음낭증에 대한 사전인지여부에 따른 비교}

부모 중 어느 한쪽이라도 급성음낭증에 대한 사전 지식이 있었던 경우는 28.7시간으로 그렇지 못한 환아의 52.9시간에 비해 짧았으며 통계학적으로 유의하였다 $(\mathrm{p}<0.05$, Table 2).

\section{고 찰}

급성음낭증은 소아에서 비교적 흔하게 관찰되며 조기진단 과 치료가 요구되는 음낭의 병적 상태를 말한다. 급성부고환 염, 고환염전, 고환수염전 및 고환염 등에 의해 발생할 수 있으며 특히 고환염전인 경우는 고환의 괴사를 유발할 수 있으므로 신속한 감별진단과 치료가 매우 중요하다. ${ }^{3}$ 급성음 낭증 중 급성부고환염이 가장 흔한 질환으로 알려져 있으며 국내에서는 소아의 급성음낭증 중 약 $60 \sim 70 \%$ 가 급성부고 환염으로 보고된 바 있다. ${ }^{4,5}$ 본 조사에서는 급성부고환염은 전체 급성음낭증의 약 $36 \%$ 로 고환염전에 비해 적었으나 이 는 본원이 3 차 의료 기관임을 감안할 때 응급수술이 필요한 고환염전 환자의 경우 1 차 및 2 차 의료 기관으로부터의 전 원이 상당수 있었기 때문으로 생각된다. 여러 연구에 의하면 급성부고환염은 사춘기 전에는 성인에 비해 적게 발생한다 고 보고되고 있으며 ${ }^{6-8}$ Melekos와 $\mathrm{Asbach}^{9}$ 는 급성부고환 
염의 원인균으로 40 세 이상에서는 일반 요로감염 세균이 많 고 40 세 이하에서는 클라미디아에 의한 감염이 많으며 하부 요로폐색 등의 배뇨장애 환자에서도 발생이 가능하다고 하 였다. Lewis 등 $^{10}$ 의 보고에 의하면 급성부고환염의 $38 \%$ 환 자에서 요로계통의 이상을 보였고 이들의 $64 \%$ 가 평소 배뇨 증상을 호소한다고 하였다. 소아의 급성부고환염의 원인에 관한 보고는 많지 않으나 소아에서의 급성부고환염의 원인 도 일반세균에 의한 상행성 감염이 원인으로 알려져 있다. ${ }^{11}$ 응급수술을 요하는 대표적인 급성음낭증으로 고환염전은 사 춘기에 주로 나타나며 급성부고환염과 같은 염증성 질환과 감별해야 하지만 신체검사나 병력청취만으로는 감별진단이 쉽지 않았다. 하지만 음낭색도플러초음파검사와 고환의 동 위원소 촬영이 이용됨으로써 진단의 정확도가 높아졌다. 색 도플러초음파검사는 비침습적이며 간편하게 시행될 수 있어 현재까지 가장 좋은 진단방법으로 알려져 있으며 민감도는 $82 \sim 4 \%$ 정도로 알려져 있다. ${ }^{12-14}$ 그러나 환자의 움직임에 따라 많은 영향을 받으므로 협조가 안되거나 의사소통이 잘 되지 않는 소아의 경우에는 수면 중에 검사를 시행하는 것 이 보다 정확한 결과를 얻을 수 있다. 고환의 동위원소 촬영 은 $89 \sim 100 \%$ 에서 고환염전을 진단할 수 있으며 ${ }^{15}$ 냉소섭 취(cold uptake)와 달무리 징후(halo sign)가 특징적으로 염증성 질환과의 감별이 가능하다. 그러나 고환주사는 작은 고환용적을 가진 소아에게는 기술적인 어려움이 많으며 ${ }^{16}$ 대 부분의 의료기관에서 주간에만 시행되는 한계가 있다. 고환 염전환자에서 고환의 보존율에 영향을 미치는 요소로 염전 후 경과된 시간, 염전의 정도, 정삭의 길이와 두께, 동맥과 정맥의 압력, 주위조직의 염증 정도 등이 알려져 있다. ${ }^{17}$ 이 중 염전의 정도에 따른 고환의 보존률에 대해서는 여러 연 구자들에 의해 밝혀져 있다. Sonda와 Lapies ${ }^{18}$ 는 개에서 고 환을 1,440 도 염전을 시켰을 때 2 시간 내 변화가 왔으며 360 도 염전을 시켰을 때 12시간까지도 별다른 변화를 볼 수 없다고 하였고 Turner ${ }^{19}$ 는 쥐실험에서 720 도 염전시킨 경우 4시간 후에 고환의 무게 및 부고환 정자농도의 감소가 있었으며 고환조직의 변성이 발생하였다고 하여 염전의 정 도가 고환의 보존율에 영향을 미친다고 하였다. 하지만 이러 한 염전의 정도보다 증상 발현 후 수술까지의 시간이 고환 염전에서 고환의 보존에 가장 중요한 요소이다. 대체로 정상 적인 고환보존의 시간은 혈류 차단 후 12 시간으로 알려져 있다. ${ }^{20,21} \mathrm{Scott}$ 등 22 의 보고에 의하면 증상발현 후 4시간 만 에 시험적 음낭절개술 후 고환정복 및 고정술을 시행한 환 자에서 고환위축이 발생하지 않은 반면 12시간에서 24시간
이후에 정복술을 시행한 2예에서는 위축을 보였다고 한다. 본 연구에서는 급성음낭증으로 내원한 환자의 평균 내원시 간은 무려 48시간이었으며 이중 고환염전인 경우 증상발현 후 수술시간까지 12 시간이 넘은 환자에서는 9 예 중 1 예만 이 고환의 보존이 가능하였다. 따라서 증상발현 후 병원 도 착까지의 시간을 줄일 수 있다면 고환의 보존율을 높일 수 있다고 생각된다. 이와 같이 고환염전의 경우 증상발현 후 수술까지의 시간이 고환의 보존에 절대적 영향을 미치지만 여러 가지 이유에 의해 증상의 발현 후 병원 방문까지의 시 간이 늦어지는 경우가 많다. 이러한 실정에서 저자들은 증상 발현 후 내원까지의 시간을 부모와 관련한 여러 인자들에 따라 비교분석하였다. 본 연구의 결과에 의하면 부모의 연령 에 따른 내원시간의 차이는 없었으나 어머니의 경우 20 대에 서 30 대보다 내원시간이 지연되는 경향을 나타내었고, 어머 니의 학력이 대졸이상인 경우, 소득수준이 월 300 만 원대 이상인 경우 및 맞벌이 부부인 경우에서 내원이 늦어졌다. 이러한 결과는 학력이 대졸이상인 기혼여성에서 직장을 가 지고 있는 경우가 많고, 맞벌이 부부일수록 월 소득이 증가 하는 것에 따른 것으로 생각된다. 특히 20대에서 자녀를 직 접 양육하기보다는 탁아시설이나 조부모 및 제 3자에 의한 양육 가능성이 높아 세심한 관찰의 부족, 환아의 수치심과 공포심 등으로 인해 증상유무를 발견하는 시간이 늦어질 수 있을 것으로 생각되며, 병원 내원도 질환에 대한 경험부족과 여유시간의 부족으로 늦어질 수 있을 것으로 생각된다. 또한 병원에서 수술까지의 시간도 평균 4.4시간으로 이는 진료를 위한 대기시간, 진단을 위해 초음파를 시행하는데 걸리는 시 간, 수술준비시간 및 환자의 금식시간 등으로 인한 것으로 생각되며 이러한 시간의 지체를 줄이기 위한 병원 응급진료 체계 및 마취과, 방사선과 등의 관련과의 협조가 필요하리라 생각된다. 환자의 나이에 따른 비교에서 6세 이상에서 통계 적 유의성은 없었으나 내원이 늦어졌는데 이는 환자가 공포 감, 수치심으로 자신의 의지에 따라 증상을 감추고 부모님께 알리지 않을 수 있는 연령이기 때문으로 생각된다. 또한 부 모들의 급성음낭증에 대한 무지로 단순 좌상이나 염증으로 인한 것으로 생각하고 방치해둔 경우도 적지 않았다. 이는 본 연구에서 부모중 어느 한쪽이 급성음낭증에 대해 사전에 알고 있었던 경우에 유의하게 내원시간이 빨랐다는 결과에 의해 뒷받침된다. 자녀의 수가 한 명인경우 둘 이상의 경우 에 비해 내원이 늦어진 것은 둘 이상의 자녀를 가진 부모일 수록 자녀를 키우는 경험이 늘고, 질환이나 문제 발생에 대 한 대처 능력이 증가한 것으로 생각된다. 최초 방문한 의료 
기관의 분포를 보면 비뇨기과의원이 $47 \%$, 소아과 및 일반 의원이 $16 \%$ 로 개원의원이 대부분을 차지한다는 점에서 개 원의원에서 최초 진료시 급성음낭증의 조기 진단 및 처치가 중요함을 알 수 있었다. 본 연구에서 어머니의 학력수준, 소 득수준, 맞벌이 여부 및 급성음낭증의 사전인지여부가 급성 음낭증 환아의 내원시간에 영향을 미치는 것으로 나타났다. 따라서 급성음낭증 환아에서 고환 보존율을 높이기 위해서 는 학동기 아동과 그 부모에 대한 본질환의 인식이 반드시 필요하며 개원의, 특히 타과의사에게도 급성음낭증에 대한 홍보, 교육 및 재인식이 필요하리라 생각한다. 이를 위해서 학교보건교육을 통해 교사, 학생을 지도하는 일과 각종 매체 를 통한 홍보나 시민대상의 의료강좌 등 학회 차원의 관심 이 필요하리라 생각된다.

\section{알 림}

이 연구는 2007년 부산대학교병원 임상연구비 지원으로 수행되었음.

\section{References}

1. Oh DK, Kim SJ, Ahn HS. Experiences of 313 cases of acute scrotum: properties of acute epididymitis and differential diagnosis of testicular torsion. Korean J Urol 2002;43:624-30.

2. Sung GT, Kim CG, Yoon KH, Yoon JH. Torsion of the spermatic cord: the need for early recognition. Korean J Urol 1995;36:431-7.

3. Lee YB, Kim DS. A clinical observation on torsion of the testis. Korean J Urol 1991;32:932-6.

4. Lee JW, Kim YT, Lee HM. Evaluation of the acute scrotum by color Doppler ultrasonography and radioisotope imaging in children. Korean J Urol 1996;37:671-6.

5. Jung SI, Joo JS, Kang TW, Kwon DD, Park K, Ryu SB. Clinical characteristics of acute epididymitis in prepubertal patients. Chonnam Med $J$ 2007;43:39-43.

6. Snyder HM III, Caldamone AA, Duckett JW Jr. Pain-scrotal. In:
Fleisher GR, Ludwig S, eds. Textbook of pediatric emergency medicine. 3rd ed. Baltimore:Williams \& Wilkins, 1993:382-7.

7. Siegel A, Snyder H, Duckett JW. Epididymitis in infants and boys: underlying urogenital anomalies and efficacy of imaging modalities. $J$ Urol 1987;138:1100-3.

8. McAninch JW. Disorders of the testis, scrotum \& spermatic cord. In: Tanogho EA, McAninch JW, eds. Smith's general urology. 15th ed. New York:Appleton \& Lange, 2000;684-93.

9. Melekos MD, Asbach HW. Epididymitis: aspects concerning etiology and treatment. $J$ Urol 1987;138:83-6.

10. Lewis AG, Bukowski TP, Jarvis PD, Wacksman J, Sheldon CA. Evaluation of acute scrotum in the emergency department. $J$ Pediatr Surg 1995;30:277-81.

11. Williams CB, Litvak AS, McRoberts JW. Epididymitis in infancy. $J$ Urol 1979;121:125-6.

12. Wilbert DM, Schaerfe CW, Stern WD, Strohmajer WL, Bichler KH. Evaluation of the acute scrotum by color-coded Doppler ultrasonography. J Urol 1993;149:1475-7.

13. Burks DD, Markey BJ, Burkhard TK, Balsara ZN, Haluszka MM, Canning DA. Suspected testicular torsion and ischemia: evaluation with color Doppler sonography. Radiology 1990;175:815-21.

14. Maroto A, Serres X, Torrent N, Figueras M Hoyo D, VelayosA. Sonographic appearance of the torsion knot in spermatic cord torsion. AJR Am J Roentgenol 1992;159:1029-30.

15. Levy OM, Gittelman MC, Strashun AM, Cohen EL, Fine EJ. Diagnosis of acute testicular torsion using radionuclide scanning. $J$ Urol 1983;129:975-7.

16. Haynes BE, Bessen HA, Haynes VE. The diagnosis of testicular torsion. JAMA 1983;249:2522-7.

17. Costabile RA, Choyke PL, Frank JA, Girton ME, Diggs R, Billups $\mathrm{KL}$, et al. Variability of ischemia during spermatic cord torsion in the rat. J Urol 1994;151:1070-2.

18. Sonda LP Jr, Lapides J. Experimental torsion of the spermatic cord. Surg Forum 1961;12:502-4.

19. Turner TT. On unilateral testicular and epididymal torsion: no effect on the contralateral testis. J Urol 1987;138:1285-90.

20. Chang HJ, Lee H, Oh YH, Kim DH, Sohn HG, Ha DB, et al. False negative of Doppler ultrasonography during testis torsion in animal model. Korean J Urol 1999;40:1235-40.

21. Skoglund RW, McRoberts JW, Ragde H. Torsion of spermatic cord: a review of the literature and an analysis of 70 new cases. $J$ Urol 1970;104:604-7.

22. Scott JH 3rd, Harty JI, Howerton LW. The management of testicular torsion in the acute pediatric scrotum. J Urol 1983;129:558-60. 